\title{
International
}

Journal of

DOI : 10.15740/HAS/IJPE/8.1/20-23

e ISSN-0976-7924 Visit us : www.researchjournal.co.in

Research Paper

Volume 8 | Issue 1 | April, 2015 | 20-23

\section{A comparative study of body composition between sprinters and throwers}

KRISHNA R. YADAV

Received : 28.06.2014; Revised : 23.02.2015; Accepted : 07.03.2015

Author for correspondence

KRISHNA. R. YADAV

M.V.A.S. Shri. K.G. Nadgir College

of Physical Education, DHARWAD

(KARNATAKA) INDIA

Email : krishnayadav1237@

yahoo.com

\section{-ABSTRACT}

The purpose of the study was to compare the body composition between sprinters and throwers. Specific anthropometric characteristics are needed to be successful in certain sporting events. It is also important to note that there are some differences in body structure and composition of sports persons involved in individual and team sports. Physical performance declines when body weight and percentage of body fat is at extreme leve, but depending on the sport, a higher or lower body fat level may be beneficial. Because of this, body composition trends in different sports can help identify potential participants. A total of 30 male (sprinters $n=15$ and throwers $n$ =15) subjects were selected from of different colleges affiliated to Karnatak University, Dharwad st: Karnataka. The ages of athletes were between 20 to 25 years. The body composition of the subjects was assessed through Skinfold measurement of four sites i.e., biceps, triceps, suprailiac and sub-scapular were measured with the help of Skinfold caliper. To the assessment of percentage fat estimated from the sum of skin folds was calculated using equations of Siri (1956) and Durnin and Womersley (1974) was used. For the data analysis, t - test was employed. Results showed that there was a significant difference between sprinters and throwers. Throwers were found to have significantly higher body density and percentage of body fat $(\mathrm{p}<0.05)$ than the sprinters, whereas Sprinters had significantly higher lean body mass $(\mathrm{p}<0.01)$ as compared to throwers. Whereas in total body mass there was no significant difference between sprinters and throwers.

- KEY WORDS : Percentage of fat body density, Lean body mass Throwers, Sprinters

- HOW TO CITE THIS PAPER : Yadav, Krishna R. (2015). A comparative study of body composition between sprinters and throwers. Internat. J. Phy. Edu., 8 (1) : 20-23. 